Article

\title{
Shielding Properties of Cement Composites Filled with Commercial Biochar
}

\author{
Muhammad Yasir ${ }^{1}$, Davide di Summa ${ }^{2}$, Giuseppe Ruscica ${ }^{2}$, Isabella Natali Sora ${ }^{2}$ and \\ Patrizia Savi 1,*(D) \\ 1 Department of Electronics and Telecommunications, Polytechnic of Turin, C.so Duca degli Abruzzi 24, 10129 \\ Torino, Italy; muhammad.yasir@polito.it \\ 2 Department of Engineering and Applied Sciences, University of Bergamo, 24044 Dalmine, Italy; \\ davide.disumma@unibg.it (D.d.S.); giuseppe.ruscica@unibg.it (G.R.); isabella.natali-sora@unibg.it (I.N.S.) \\ * Correspondence: patrizia.savi@polito.it
}

Received: 11 May 2020; Accepted: 14 May 2020; Published: 16 May 2020

check for updates

\begin{abstract}
The partial substitution of non-renewable materials in cementitious composites with eco-friendly materials is promising not only in terms of cost reduction, but also in improving the composites' shielding properties. The water and carbon content of a commercial lignin-based biochar is analyzed with thermal gravimetric analysis. Cementitious composite samples of lignin-based biochar with $14 \mathrm{wt} . \%$ and $18 \mathrm{wt} . \%$ are realized. Good dispersion of the filler in the composites is observed by SEM analysis. The samples are fabricated in order to fit in a rectangular waveguide for measurements of the shielding effectiveness in the X-band. A shielding effectiveness of $15 \mathrm{~dB}$ was obtained at a frequency of $10 \mathrm{GHz}$ in the case of composites with $18 \mathrm{wt} . \%$ biochar. Full-wave simulations are performed by fitting the measured shielding effectiveness to the simulated shielding effectiveness by varying material properties in the simulator. Analysis of the dimensional tolerances and thickness of the samples is performed with the help of full/wave simulations. Lignin-based biochar is a good candidate for partial substitution of cement in cementitious composites, as the shielding effectiveness of the composites increases substantially.
\end{abstract}

Keywords: shielding effectiveness; biochar; eco-friendly material; cementitious composites; waveguides

\section{Introduction}

The human population saw rapid growth in the past few decades. With increasing population, the demand for the construction industry increased manifold [1]. This resulted in increasing greenhouse gas emissions from cement production [2]. The substitution of non-renewable raw materials used in the construction industry with eco-friendly materials derived from waste is promising in terms of cost and environmental protection [3]. Agriculture and forestry waste is primarily burnt on field in order to reduce the cost of disposal. When converted into biochar, this waste can be used as a partial substitute to cement, resulting in a significant reduction in greenhouse gas emissions and improving the mechanical properties of concrete [4,5].

An increasing number of devices working at microwave- and millimeter-wave frequencies resulted in an overall increase in electromagnetic radiation [6,7]. Electromagnetic shields are deployed to protect sensitive devices against electromagnetic interference [8,9]. In places that are vulnerable to electromagnetic interference, shielding materials can be applied as a coating on wall surfaces [10]. A number of devices working at microwave- and millimeter-wave frequencies are used in the health sector for applications like imaging, tomography, etc. [11,12]. The X-band in particular is important for radar communications including air-traffic control, weather monitoring, maritime vessel traffic control, 
defense tracking, and vehicle speed detection. The use of shielding materials in buildings can be helpful in isolating equipment that is sensitive to electromagnetic interferences $[13,14]$. Different measurement techniques can be deployed for the determination of the shielding effectiveness of materials. The most common measurement techniques are: reverberation chamber [15], free-space measurements in an anechoic chamber [16], and coaxial and waveguide methods [17-19]. Each measurement technique requires specific sample dimensions and frequency band. The X-band is very important for applications like satellite communications and radar.

The use of carbon-based materials in epoxy composites and the analysis of their morphological and electrical properties were vastly studied [20-23]. Conventional carbon-based materials like graphene and carbon nanotubes are expensive and require complex synthesis. In recent years, the use of biochar-substituted carbon nanotubes and graphene in composites as filler was investigated [24,25]. Biochar is cost-effective as compared to other carbon-based materials. Biochar is a porous carbonaceous material produced by thermal treatment of biomass in the absence of oxygen [26]. It can be made from a number of different waste products such as agricultural waste, food waste, or sewage sludge [27]. Until recently, biochar was used for soil amendment in agriculture and landfilling applications [28]. The use of biochar in alternative applications is being studied at a vast scale, specifically for carbon sequestration, for energy storage applications [29], and in construction and building [30,31].

In this paper, lignin-based commercial biochar was used as a partial substitute to cement in composites. The water, carbon, and other residues of the biochar were studied by thermogravimetric analysis (TGA). Composites of $4 \mathrm{~mm}$ thickness with plain cement, $14 \mathrm{wt} . \%$ biochar, and $18 \mathrm{wt} . \%$ biochar were fabricated with specific dimensions for measurements of the shielding effectiveness inside a waveguide working in the $\mathrm{X}$-band microwave frequency. The samples with $18 \mathrm{wt} . \%$ biochar were cured in water for seven days or 28 days. For examining the microstructural properties of the composites and dispersion of the filler in the composite matrix, SEM was adopted. Measurements of the shielding effectiveness were compared with simulated results obtained with a full-wave simulator. As expected, the shielding effectiveness increased with the increase of the percentage of filler $(11 \mathrm{~dB}$ for $14 \mathrm{wt} . \%$, and $15 \mathrm{~dB}$ for $18 \mathrm{wt} . \%$ at $10 \mathrm{GHz}$ ). Analyses of fabrication tolerances and sample thickness were performed with the help of a full-wave simulator.

Finally, the effect of the curing period in water on the shielding effectiveness values was analyzed for the samples with $18 \mathrm{wt}$.\% biochar. The shielding effectiveness increased by approximately $5 \mathrm{~dB}$ in the whole frequency range for the sample cured in water for 28 days with respect to the sample cured in water for seven days.

\section{Materials and Methods}

\subsection{Composites Preparation}

The composite samples produced were with $14 \mathrm{wt.} \%$ and $18 \mathrm{wt} . \%$ biochar in Portland cement (PC). For the sake of comparison, a composite without biochar was also produced, which is referred to as plain cement composite. The biochar used to realize the samples was a commercial product provided by Carlo Erba Reagents. It was pyrolyzed in the form of powder at a temperature of $750{ }^{\circ} \mathrm{C}$ for four hours in an alumina crucible. For preparation of cementitious composites, ordinary Portland Cement (PC) (grade $52.5 \mathrm{R}$ ) compliant with ASTM C150 was used along with water and superplasticizer to form an adequate consistency of the paste. The percentages of water and superplasticizer used were equal to $60 \mathrm{wt} . \%$ and $1.8 \mathrm{wt} . \%$, respectively. A mechanical mixer was used to work the mixture for a duration of $5 \mathrm{~min}$. Silicon molds of adequate shape and size were then used to give the composites the required shape and dimensions.

Portland cement was blended with biochar by using a mechanical mixer for 5 min with two different percentages by weight of cement, $14 \%$ and $18 \%$, water $(60 \%)$, and superplasticizer $(1.8 \%)$. Furthermore, a reference specimen was realized using only Portland cement matrix blended together with water and superplasticizer equal to $35 \%$ and $1.5 \%$. The obtained composites were then poured 
into rectangular silicone molds for shielding effectiveness analysis. The silicon molds were fabricated in a three-dimensional (3D) printed master mold of specific dimensions (see Figure 1). The reusable and flexible silicone molds helped with easy extraction of composite samples once they were cured.

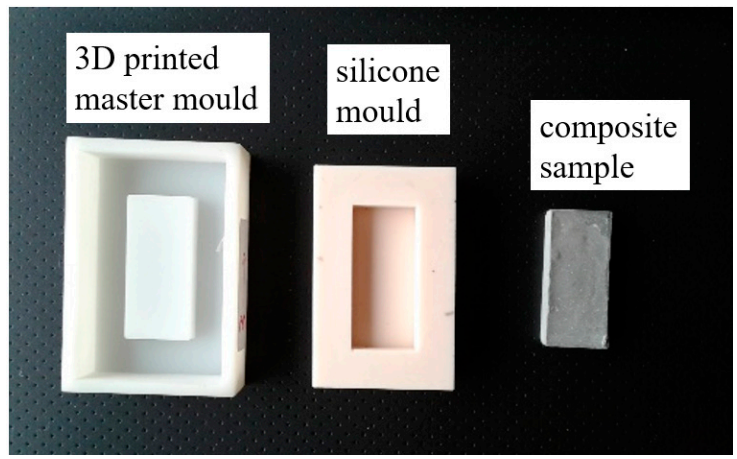

Figure 1. Three-dimensional (3D) printed master mold with silicone mold and an example of a composite sample.

Initially, the composite samples were kept at a relative humidity of $90 \% \pm 5 \%$ for $24 \mathrm{~h}$. The composites were then demolded and immersed in water at a temperature of $20 \pm 2{ }^{\circ} \mathrm{C}$. The samples were then cured in water for a period of seven days. Two different curing methodologies were used for curing of the $18 \mathrm{wt} . \%$ samples in water for seven days and 28 days, in order to evaluate the impact of water curing duration on the shielding effectiveness (see Table 1). In Table 1, the different steps of fabrication and measurements of the cement composites are reported.

Table 1. Fabrication and measurements of the cement composites.

\begin{tabular}{|c|c|c|c|c|}
\hline Day & Plain Cement & 14 wt. $\%$ (7 days) & 18 wt. $\%$ (7 days) & 18 wt. $\%$ ( 28 days) \\
\hline 0 & Fabrication & Fabrication & Fabrication & Fabrication \\
\hline 1 & Demolded & Demolded & Demolded & Demolded \\
\hline 1 & Cured in water & Cured in water & Cured in water & Cured in water \\
\hline 7 & Extracted from water & Extracted from water & Extracted from water & - \\
\hline 21 & SE meas.* 2 weeks & SE meas.* 2 weeks & SE meas.* 2 weeks & - \\
\hline 28 & - & - & - & Extracted from water \\
\hline 42 & - & - & - & SE meas. ${ }^{*} 2$ weeks \\
\hline 70 & SE meas. ${ }^{*} 10$ weeks & SE meas. ${ }^{*} 10$ weeks & SE meas.* 10 weeks & - \\
\hline 98 & - & - & - & SE meas.* 10 weeks \\
\hline
\end{tabular}

* Shielding effectiveness measurement (SE meas.)

\subsection{Morphological Analysis}

Thermogravimetric analyses (TG-DTA) were carried out in air using about $20 \mathrm{mg}$ of biochar heated from room temperature to $950{ }^{\circ} \mathrm{C}$ at $3{ }^{\circ} \mathrm{C} / \mathrm{min}$. For a morphological characterization of the cement composites, a scanning electron microscope (Hitachi S-2500C, Hitachi, Japan) was used for the analysis of the cross-section of cement composites with $18 \mathrm{wt} . \%$ biochar. Sections of the composite were cut and polished with measurements performed on gold-plated samples to avoid any charging effects.

\subsection{Radiofrequency Measurements}

The total shielding effectiveness can be defined as the ratio of the incident and transmitted field. It can be obtained from the measured transmission loss $\left(S_{21}\right)$ in a waveguide as follows:

$$
S E=-20 \cdot \log \left(\left|S_{21}\right|\right) \text {. }
$$


The total shielding effectiveness of a material comprises dissipation loss, $L_{D}$, and mismatch loss, $L_{M}[32]$.

$$
S E=L_{D}+L_{M}
$$

where $L_{M}$ can be calculated from the reflection scattering parameter as follows:

$$
\begin{aligned}
& L_{M}=-10 \cdot \log _{10}\left(1-\left|S_{11}\right|^{2}\right), \\
& L_{D}=-10 \cdot \log _{10}\left(\frac{\left|S_{21}\right|^{2}}{1-\left|S_{11}\right|^{2}}\right) .
\end{aligned}
$$

The scattering parameters of the composites were measured in a WR90 (Sivers IMA, Holding $\mathrm{AB}(\mathrm{HQ})$, Sweden) rectangular waveguide from $8 \mathrm{GHz}$ to $12 \mathrm{GHz}$ using a set-up similar to that in Reference [33]. The samples were fabricated in order to fit the rectangular waveguide cross-section ( $a=22.86 \mathrm{~mm}, b=10.16 \mathrm{~mm}$ ). The thickness of the samples was $4 \mathrm{~mm}$. The set-up is shown in Figure 2. It consisted of a two-port vector network analyzer (VNA) (Agilent E8361A: Keysight, Santa Rosa, CA 81841, USA), two coaxial cables connected to the two ports of the network analyzer, two coaxial-to-waveguide adapters, and two rectangular waveguides. Between the waveguide flanges, a spacer holding the sample was inserted. Before the measurements, a two-port calibration (short, matched load, thru) was performed. The reference planes were at the ends of the spacer.

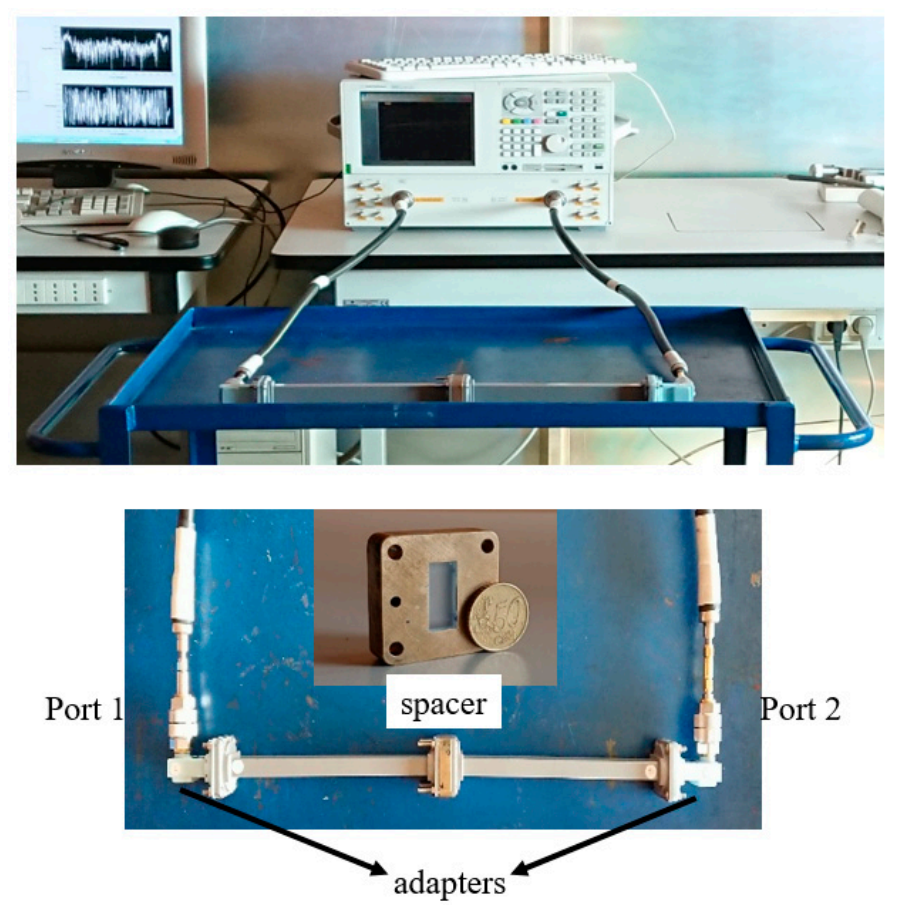

Figure 2. WR90 waveguide measurement set-up.

\subsection{Finite Element Simulations}

A commercial finite element modeling tool, Ansys HFSS, was used to simulate the waveguide with the composite sample as shown in Figure 3. The material properties of the composite inserted in the waveguide were chosen by fitting the simulated shielding effectiveness values to the measured shielding effectiveness values. The composite dimensions and thickness were varied to analyze the impact of fabrication tolerances and thickness on the values of shielding effectiveness. 


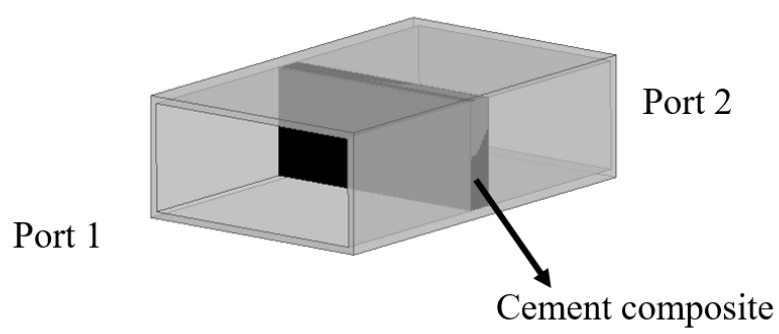

(a)

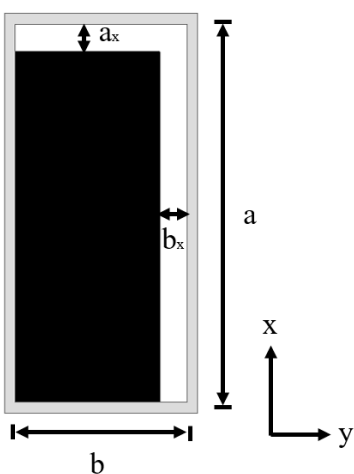

(b)

Figure 3. Geometrical configuration of the waveguide: (a) geometry of the simulated waveguide with composite. (b) Cross-section of the waveguide for the dimensional analysis.

\subsection{Dimensional Tolerance Analysis}

In order to take into account the dimensional tolerance of the cement composite, simulations were performed based on varying the two dimensions along the $x$-axis and $y$-axis (see Figure 3 ). In the case of plain cement composites, it was found that there was negligible variation of the transmission properties by varying the $a_{x}$ dimension of the sample, while the impact of the variation of $b_{x}$ was significant. A variation of $0.5 \mathrm{~mm}$ in $b_{x}$ resulted in a variation of almost $1 \mathrm{~dB}$ in the transmission coefficient, as shown in Figure 4. It was ensured that the tolerance in the dimensions of the cement composites was below this value.

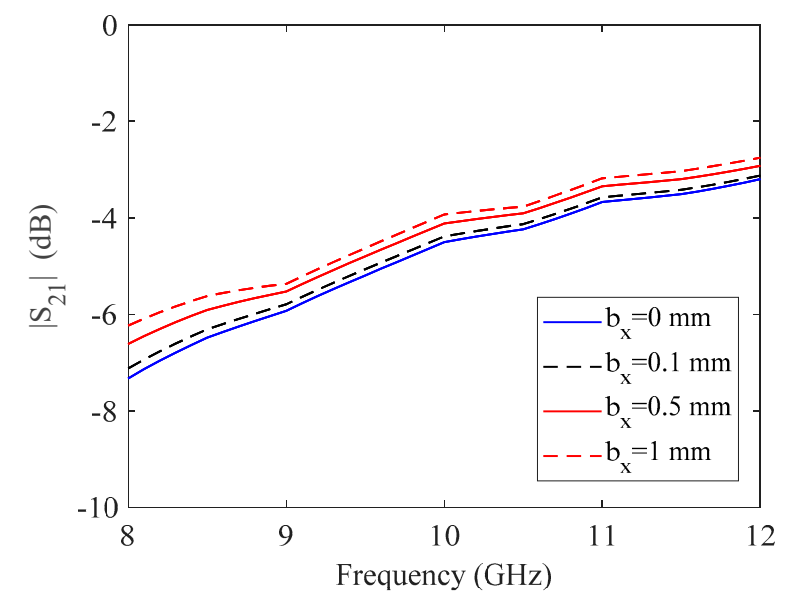

Figure 4. Analysis of fabrication tolerances of the plain cement composites.

\section{Results}

\subsection{Biochar and Composite Characterization}

The water and carbon content of the biochar was investigated by TG-DTA experiments. The TGA curve of biochar is reported in Figure 5. Below $100{ }^{\circ} \mathrm{C}$, the weight loss was about $16 \%$, due to the evaporation of the physically adsorbed water. From $350{ }^{\circ} \mathrm{C}$ to $500{ }^{\circ} \mathrm{C}$, the weight loss was due to the combustion of the graphitic carbon fraction (about $74 \%$ of the total weight of the sample). At $950{ }^{\circ} \mathrm{C}$, a residue of around $5 \%$ in weight was observed with respect to the initial amount. 


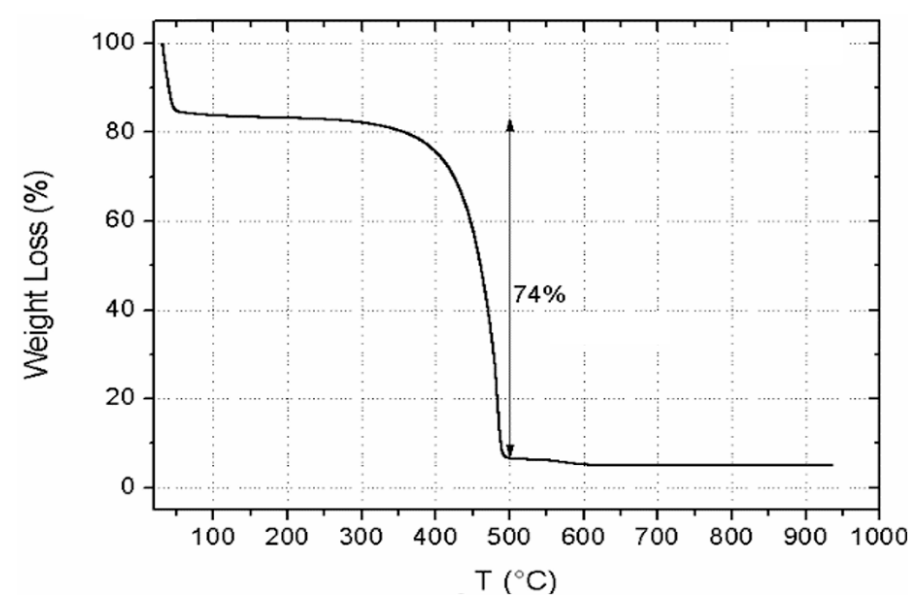

Figure 5. Thermogravimetric analysis (TGA) curve of biochar filler.

Figure 6 illustrates the SEM image of composites with the highest content of biochar (18 wt.\%) recorded with secondary electrons. The black structures shown in the SEM image are the carbonaceous particles. The expected elongated structure of the particles was due to the fiber origin of the biochar. The particles showed a good dispersion in the matrix.

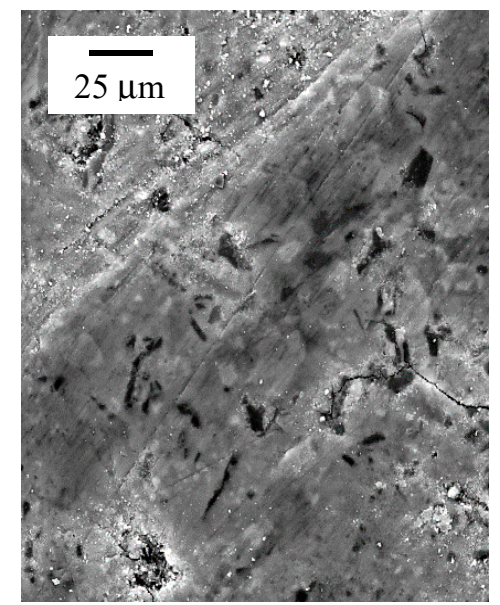

Figure 6. SEM micrograph of cement containing biochar $18 \%$ at $1000 \times$ magnification.

\subsection{Shielding Effectiveness Analysis}

Shielding effectiveness can be found from the measured transmission coefficient, $S_{21}$, in a waveguide (see Figure 2), as defined in Equation (1). The measured shielding effectiveness values of the plain cement used as a reference sample, as well as the sample with $14 \mathrm{wt} . \%$ and $18 \mathrm{wt} . \%$ filler cured in water for seven days, measured after 10 weeks, are shown in Figure 7 . At the center frequency of $10 \mathrm{GHz}$, the shielding effectiveness of plain cement was almost $5 \mathrm{~dB}$, which increased to $11 \mathrm{~dB}$ for the samples with $14 \mathrm{wt} . \%$ biochar. The maximum shielding effectiveness measured for the sample with $18 \mathrm{wt} . \%$ was around $15 \mathrm{~dB}$. These results were obtained with 4 -mm-thick samples. The shielding effectiveness values could be further increased by increasing the sample thickness and/or the percentage of biochar. The shielding effectiveness of the plain cement composites decreased with frequency. This behavior is similar to other cement composites [34]. The different behavior in terms of the frequency of the biochar composites with respect to plain cement composites can be attributed to the presence of entrapped water in the biochar [35]. 


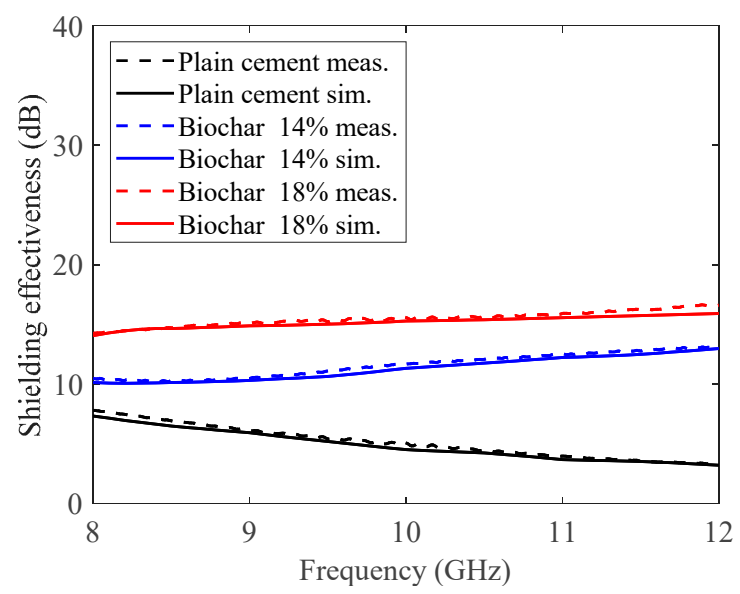

Figure 7. Measured and simulated shielding effectiveness values for plain cement, as well as the sample with $14 \mathrm{wt} . \%$ biochar and the sample with $18 \mathrm{wt} . \%$. Samples were cured for seven days in water. Measurements were performed after 10 weeks of aging.

In Figure 7, the simulated shielding effectiveness obtained with full-wave simulations are reported (dashed lines). The values of complex permittivity were varied to fit the simulated shielding effectiveness values to the measured shielding effectiveness values, and a good correlation between the measured and simulated data was obtained.

There is a strong correlation between the curing period in water and the mechanical strength of cement composites [30]. In order to evaluate the effect of the curing period in water on the shielding effectiveness values, samples with $18 \mathrm{wt} . \%$ biochar cured in water for a period of seven days and 28 days were analyzed. The shielding effectiveness of the cement composite with $18 \mathrm{wt} . \%$ biochar cured in water for seven days and 28 days, measured after two weeks and 10 weeks, are shown in Figure 8 . It can be seen that the sample cured in water for 28 days had higher shielding effectiveness when measured both after two weeks and after 10 weeks. The variation of the shielding effectiveness over time of the cement composite cured for 28 days was also higher than that cured in water for seven days. This shows that the shielding effectiveness increased due to the presence of water, whereby the loss of water from the sample over time resulted in a reduced value of the shielding effectiveness.

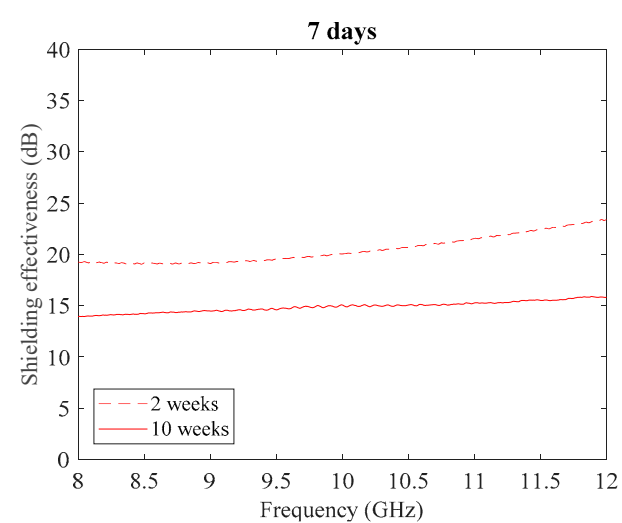

(a)

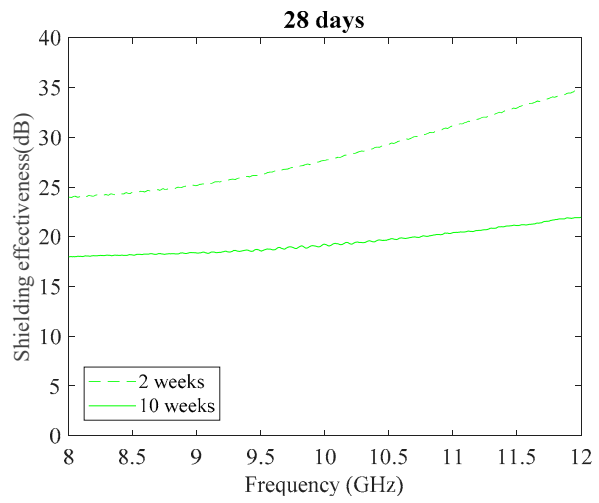

(b)

Figure 8. Measured shielding effectiveness of cement sample with $18 \mathrm{wt}$.\% biochar: (a) cured in water for seven days; (b) cured in water for 28 days. Measurements were performed after two weeks and 10 weeks.

\section{Discussions}

In order to evaluate the impact of the presence of biochar in the cement composites on the shielding effectiveness, a comparison was performed with other studies in the literature (see Table 2). 
The case considered in this comparison was the composite filled with $18 \mathrm{wt} . \%$ biochar cured in water for seven days and measured after 10 weeks. The thickness of the samples considered was $4 \mathrm{~mm}$, which provided a shielding effectiveness value of almost $14 \mathrm{~dB}$. In comparison with the literature, other reported cement samples gave higher shielding effectiveness values due to a higher value of thickness. In order to evaluate the impact of the thickness on the shielding effectiveness, simulations were performed with higher thickness values. The results are shown in Figure 9. As expected, the shielding effectiveness increased considerably upon increasing the thickness of the sample.

Table 2. Comparison with the literature.

\begin{tabular}{cccccc}
\hline Reference & Frequency & $\begin{array}{c}\text { Measured } \\
\text { After (days) }\end{array}$ & $\begin{array}{c}\text { Thickness } \\
(\mathbf{m m})\end{array}$ & $\begin{array}{c}\text { Shielding } \\
\text { Effectiveness (dB) }\end{array}$ & Materials \\
\hline$[34]$ & $3 \mathrm{GHz}$ & 36 & 100 & 17.5 & Cement \\
{$[36]$} & $10 \mathrm{GHz}$ & 95 & 150 & 20 & Cement \\
This work & $10 \mathrm{GHz}$ & 70 & 4 & 15 & Cement +18 wt. \% biochar \\
\hline
\end{tabular}

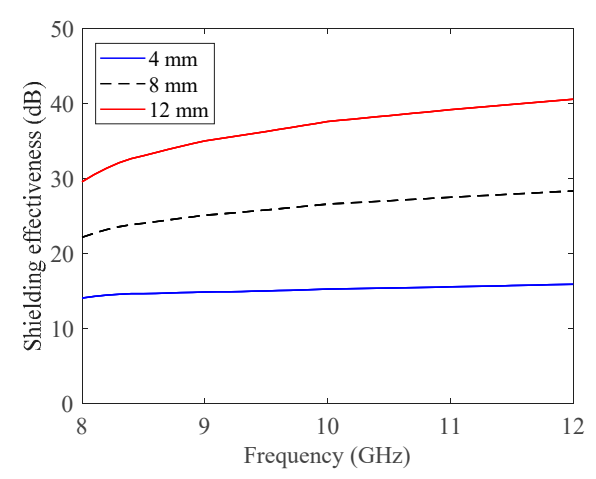

Figure 9. Simulated results for cement composites with $18 \mathrm{wt}$ \% biochar with different thicknesses.

\section{Conclusions}

Biochar is obtained by thermal treatment of waste products. It is vastly used for soil amendment. More recently, it was used for applications such as energy storage, carbon sequestration, and construction. The effect of a commercial biochar on the shielding properties of cement composites was investigated in the X-band. The conclusions drawn based on the results presented can be extended to other microwave frequencies. Cementitious composites with ordinary Portland Cement (PC) were prepared without biochar and with biochar as filler (14 wt.\% and $18 \mathrm{wt} . \%)$. Samples were prepared in order to fit a WR90 waveguide $(8-12 \mathrm{GHz})$. With the help of a full-wave simulator, the fabrication tolerances of the samples were analyzed. A variation of $\pm 0.5 \mathrm{~mm}$ resulted in a change of the shielding effectiveness of $\pm 1 \mathrm{~dB}$. Shielding effectiveness can be obtained from the measurements of scattering parameters. Samples with $14 \mathrm{wt} . \%$ and $18 \mathrm{wt} . \%$ biochar as filler were cured in water for seven days. As expected, the shielding effectiveness increased with the increase in the percentage of filler $(11 \mathrm{~dB}$ for $14 \mathrm{wt} . \%$, and $15 \mathrm{~dB}$ for $18 \mathrm{wt} . \%$ at $10 \mathrm{GHz}$ ). In order to evaluate the effect of the curing period in water on the shielding effectiveness, different curing periods were analyzed. Samples with $18 \mathrm{wt} . \%$ biochar were cured in water for a period of seven days and 28 days. The shielding effectiveness increased by approximately $5 \mathrm{~dB}$ in the whole frequency range for the samples cured in water for 28 days as compared to samples cured in water for seven days.

Author Contributions: Composite fabrication, D.d.S. and G.R.; waveguide measurements and discussion of the shielding effectiveness, D.d.S., M.Y., and P.S.; microstructure characterization and TGA, I.N.S.; full-wave simulations, M.Y.; original draft preparation, M.Y. and P.S.; writing—review and editing, M.Y., P.S., and I.N.S.; supervision, P.S.; conceptualization, M.Y., P.S., and I.N.S., funding acquisition, G.R. All authors read and agreed to the published version of the manuscript.

Funding: This research received no external funding.

Acknowledgments: The authors would like to thank Renato Pelosato for TGA measurements. 
Conflicts of Interest: The authors declare no conflict of interest.

\section{References}

1. Klee, H. Briefing: The Cement Sustainability Initiative. Proc. Inst. Civ. Eng._Eng. Sustain. 2004, 157, 9-11. [CrossRef]

2. Oh, D.-Y.; Noguchi, T.; Kitagaki, R.; Park, W.-J. $\mathrm{CO}_{2}$ emission reduction by reuse of building material waste in the Japanese cement industry. Renew. Sust. Energ. Rev. 2014, 38, 796-810. [CrossRef]

3. Balasubramanian, J.; Gopal, E.; Periakaruppan, P. Strength and microstructure of mortar with sand substitutes. Graevinar 2016, 68, 29-37.

4. Van der Lugt, P.; Van den Dobbelsteen, A.A.J.F.; Janssen, J.J.A. An environmental, economic and practical assessment of bamboo as a building material for supporting structures. Constr. Build. Mater. 2006, 20, 648-656. [CrossRef]

5. Klapiszewski, Ł.; Klapiszewska, I.; Ślosarczyk, A.; Jesionowski, T. Lignin-Based Hybrid Admixtures and their Role. Cem. Compos. Fabr. Mol. 2019, 24, 3544.

6. Research and Markets. Available online: https://www.researchandmarkets.com/research/6mzxvg/ microwave_devices (accessed on 25 February 2020).

7. Delhi, N.; Behari, G. Electromagnetic pollution-the causes and concerns. In Proceedings of the International Conference of Electromagnetic Interference and Compatibility, Bangalore, India, 23 February 2002.

8. McKerchar, W.D. Electromagnetic Compatibility of High Density Wiring Installations by Design or Retrofit. IEEE Trans Elm. Comp. 1965, 7, 1-9. [CrossRef]

9. Wang, Y.; Gordon, S.; Baum, T.; Su, Z. Multifunctional Stretchable Conductive Woven Fabric Containing Metal Wire with Durable Structural Stability and Electromagnetic Shielding in the X-Band. Polymers 2020, 12, 399. [CrossRef]

10. Lee, H.S.; Park, J.H.; Singh, J.K.; Choi, H.J.; Mandal, S.; Jang, J.M.; Yang, H.M. Electromagnetic Shielding Performance of Carbon Black Mixed Concrete with Zn-Al Metal Thermal Spray Coating. Materials 2020, 13, 895. [CrossRef]

11. Mojtaba, A.; Maryam, I.; Saripan, A.; Iqbal, M.; Hasan, W.Z.W. Three dimensions localization of tumors in confocal microwave imaging for breast cancer detection. Microw. Opt. Technol. Lett. 2015, 57, 2917-2929.

12. Peng, K.C.; Lin, C.C.; Li, C.F.; Hung, C.Y.; Hsieh, Y.S.; Chen, C.C. Compact X-Band Vector Network Analyzer for Microwave Image Sensing. IEEE Sens. J. 2019, 9, 3304-3313. [CrossRef]

13. Hanada, E.; Watanabe, Y.; Antoku, Y.; Kenjo, Y.; Nutahara, H.; Nose, Y. Hospital construction materials: Poor shielding capacity with respect to signals transmitted by mobile telephones. Biomed. Instrum. Technol. 1998, 32, 489-496. [PubMed]

14. Khushnood, R.A.; Ahmad, S.; Savi, P.; Tulliani, J.M.; Giorcelli, M.; Ferro, G.A. Improvement in electromagnetic interference shielding effectiveness of cement composites using carbonaceous nano/micro inerts. Constr. Build. Mater. 2015, 85, 208-216. [CrossRef]

15. Holloway, C.L.; Hill, D.A.; Ladbury, J.; Koepke, G.; Garzia, R. Shielding effectiveness measurements of materials using nested reverberation chambers. IEEE Trans. Electromagn. Compat. 2003, 45, 350-356. [CrossRef]

16. Jung, M.; Lee, Y.-S.; Hong, S.-G. Effect of Incident Area Size on Estimation of EMI Shielding Effectiveness for Ultra-High Performance Concrete With Carbon Nanotubes. IEEE Access 2019, 17, 183106-183117. [CrossRef]

17. Tamburrano, A.; Desideri, D.; Maschio, A.; Sarto, S. Coaxial Waveguide Methods for Shielding Effectiveness Measurement of Planar Materials Up to 18 GHz. IEEE Trans. Electromagn. Compat. 2014, 56, 1386-1395. [CrossRef]

18. Valente, R.; Ruijter, C.D.; Vlasveld, D.; Zwaag, S.V.D.; Groen, P. Setup for EMI Shielding Effectiveness Tests of Electrically Conductive Polymer Composites at Frequencies up to $3.0 \mathrm{GHz}$. IEEE Access 2017, 5, 16665-16675. [CrossRef]

19. Rudd, M.; Baum, T.C.; Ghorbani, K. Determining High-Frequency Conductivity Based on Shielding Effectiveness Measurement Using Rectangular Waveguides. IEEE Trans. Instrum. Meas. 2020, 69, 155-162. [CrossRef]

20. Gupta, S.; Tai, N.H. Carbon materials and their composites for electromagnetic interference shielding effectiveness in X-band. Carbon 2019, 152, 159-187. [CrossRef] 
21. Giorcelli, M.; Savi, P.; Yasir, M.; Miscuglio, M.; Yahya, M.H.; Tagliaferro, A. Investigation of epoxy resin/multiwalled carbon nanotube nanocomposites behavior at low frequency. J. Mater. Res. 2014, 30, 101-107. [CrossRef]

22. Savi, P.; Yasir, M.; Giorcelli, M.; Tagliaferro, A. The effect of carbon nanotubes concentration on complex permittivity of nanocomposites. Prog. Electromagn. Res. M 2017, 55, 203-209. [CrossRef]

23. Khan, A.; Savi, P.; Quaranta, S.; Rovere, M.; Giorcelli, M.; Tagliaferro, A.; Rosso, C.; Jia, C.Q. Low-Cost Carbon Fillers to Improve Mechanical Properties and Conductivity of Epoxy Composites. Polymers 2017, 9, 642. [CrossRef] [PubMed]

24. Peterson, S.C. Evaluating corn starch and corn stover biochar as renewable filler in carboxylated styrene butadiene rubber composites. J. Elastomers Plast. 2011, 44, 43-54. [CrossRef]

25. Giorcelli, M.; Savi, P.; Khan, A.; Tagliaferro, A. Analysis of biochar with different pyrolysis temperatures used as filler in epoxy resin composites. Biomass Bioenergy 2019, 122, 466-471. [CrossRef]

26. Bridgwater, A.V. Review of fast pyrolysis of biomass and product upgrading. Biomass Bioenergy 2012, 38, 68-94. [CrossRef]

27. Savi, P.; Yasir, M.; Bartoli, M.; Giorcelli, M.; Longo, M. Electrical and Microwave Characterization of Thermal Annealed Sewage Sludge Derived Biochar Composites. Appl. Sci. 2020, 10, 1334. [CrossRef]

28. Ding, Y.; Liu, Y.; Liu, S.; Li, Z.; Tan, X.; Huang, X.; Zeng, G.; Zhou, L.; Zheng, B. Biochar to improve soil fertility. A review. Agron. Sustain. Dev. 2016, 36, 36. [CrossRef]

29. Ngan, A.; Jia, C.Q.; Tong, S.-T. Production, Characterization and Alternative Applications of Biochar. In Production of Materials from Sustainable Biomass Resources; Springer: Singapore, 2019; pp. 117-151.

30. Gupta, S.; Kua, H.W.; Low, C.Y. Use of biochar as carbon sequestering additive in cement mortar. Cem. Concr. Compos. 2018, 87, 110-129. [CrossRef]

31. Gupta, S.; Kua, H.W.; Pang, S.D. Effect of biochar on mechanical and permeability properties of concrete exposed to elevated temperature. Constr. Build. Mater. 2020, 234, 117338. [CrossRef]

32. Savi, P.; Yasir, M. Waveguide measurements of biochar derived from sewage sludge. Electron. Lett. 2020, 56, 335-337. [CrossRef]

33. Savi, P.; Cirielli, D.; di Summa, D.; Ruscica, G.; Sora, I.N. Analysis of shielding effectiveness of cement composites filled with pyrolyzed biochar. In Proceedings of the 2019 IEEE 5th International forum on Research and Technology for Society and Industry (RTSI), Florence, Italy, 9-12 September 2019; pp. 376-379.

34. Donnell, K.M.; Zoughi, R.; Kurtis, K.E. Demonstration of Microwave Method for Detection of Alkali-Silica Reaction (ASR) Gel in Cement-Based Materials. Cem. Concr. Res. 2013, 44, 1-7. [CrossRef]

35. Mrad, R.; Chehab, G. Mechanical and Microstructure Properties of Biochar-Based Mortar: An Internal Curing Agent for PCC. Sustainability 2019, 11, 2491. [CrossRef]

36. Kharkovsky, S.N.; Akay, M.F.; Hasar, U.C.; Atis, C.D. Measurement and monitoring of microwave reflection and transmission properties of cement-based specimens. IEEE Trans. Instrum. Meas. 2002, 51, 1210-1218. [CrossRef]

(C) 2020 by the authors. Licensee MDPI, Basel, Switzerland. This article is an open access article distributed under the terms and conditions of the Creative Commons Attribution (CC BY) license (http://creativecommons.org/licenses/by/4.0/). 